\title{
Interactions of ghrelin signaling pathways with the GH neuroendocrine axis: a new and experimentally tested model
}

\author{
Clemens Wagner, S Roy Caplan ${ }^{1,2}$ and Gloria S Tannenbaum ${ }^{3}$ \\ Institute of Pharmacology, University of Bern, 3010 Bern, Switzerland \\ ${ }^{1}$ Department of Biological Chemistry, Weizmann Institute of Science, Rehovot 76100 , Israel \\ ${ }^{2}$ Department of Physiology, McGill University, Montreal, Québec, Canada H3G 1 Y6 \\ ${ }^{3}$ Neuropeptide Physiology Laboratory, Departments of Pediatrics and Neurology and Neurosurgery, McGill University-Montreal Children's Hospital Research Institute, \\ McGill University, 2300 Tupper Street, PT 227, Montreal, Québec, Canada H3H 1P3 \\ (Correspondence should be addressed to G S Tannenbaum; Email: gloria.tannenbaum @mcgill.ca)
}

\begin{abstract}
Growth hormone $(\mathrm{GH})$ is secreted in a pulsatile fashion from the pituitary gland into the circulation. Release is governed by two hypothalamic neuropeptides, growth hormone-releasing hormone (GHRH) and somatostatin (SRIF), resulting in secretion episodes with a periodicity of $3.3 \mathrm{~h}$ in the male rat. Ghrelin is an additional recently identified potent $\mathrm{GH}$-secretagogue. However, its in vivo interactions with the $\mathrm{GH}$ neuroendocrine axis remain to be elucidated. Moreover, two different sites of ghrelin synthesis are involved, the stomach and the hypothalamus. We used our previously developed core model of $\mathrm{GH}$ oscillations and added the sites of ghrelin action at the pituitary and in the hypothalamus. With this extended model, we simulated the effects of central and peripheral ghrelin injections, monitored the GH profile and compared it with existing experimental results. Systemically administered ghrelin elicits a GH pulse independent of SRIF, but only in the presence of GHRH. The peripheral ghrelin signal is mediated to the brain via the vagus nerve, where it augments the release of GHRH and stimulates the secretion of neuropeptide-Y (NPY). By contrast, centrally administered ghrelin initiates a GH pulse by increasing the GHRH level and by antagonizing the SRIF block at the pituitary. In addition, NPY neurons are activated, which trigger a delayed SRIF surge. The major novel features of the present model are a) the role played by NPY, and b) the dissimilar functions of ghrelin in the hypothalamus and at the pituitary. Furthermore, the predictions of the model were experimentally examined and confirmed.
\end{abstract}

Journal of Molecular Endocrinology (2009) 43, 105-119

\section{Introduction}

In all mammalian species studied thus far, growth hormone $(\mathrm{GH})$ is secreted in a pulsatile fashion from the pituitary gland into the circulation. The release of $\mathrm{GH}$ is governed by a complex interaction of two hypothalamic hormones, growth hormone-releasing hormone (GHRH), and somatostatin (SRIF) which, in the male rat, results in GH secretory episodes with a periodicity of $3.3 \mathrm{~h}$ (Tannenbaum \& Martin 1976). In our previous work, we developed a model for generation of the ultradian GH rhythm in the rat (Wagner et al. 1998). In that model, GHRH induces the release of GH into the circulating blood, whereas SRIF blocks it. Furthermore, we postulated that the GHRH-containing neurons oscillate with a $\sim 1 \mathrm{~h}$ rhythm. Modeling of this was accomplished by introducing a feedback loop of GH on SRIF neurons in the hypothalamus that synthesize the GH receptors (GH-R; see Wagner et al. (1998)).

The recent discovery of the hormone ghrelin, which represents the endogenous ligand for the GH-secretagogue receptor (GHS-R; Kojima et al. 1999), has added an additional complexity to the GH neuroendocrine axis. Two different sites of ghrelin synthesis are involved - the stomach (original site of discovery) and the hypothalamus (Kojima et al. 1999, Sato et al. 2005). Ghrelin shows potent GH-release activity when administered either centrally or peripherally (Kojima et al. 1999, Date et al. 2000, Tolle et al. 2001, Tannenbaum et al. 2003) and it is also a powerful orexigenic hormone stimulating feeding and body weight gain (Tschöp et al. 2000). However, its in vivo interaction with the $\mathrm{GH}$ neuroendocrine axis to generate the GH rhythm remains to be elucidated.

In the rat with food available ad libitum, the ghrelin profile in blood shows small-amplitude variations with peaks irregularly distributed over time, which would be difficult to attribute to a regulatory process; this is supported by the fact that no correlation between the GH-plasma level and the ghrelin concentration has been observed in either rat (Tolle et al. 2002) or human (Avram et al. 2005). In addition, circulating ghrelin revealed the highest value of approximate entropy (ApEn), a measure of irregularity, when compared to

DOI: 10.1677/JME-09-0023 Online version via http://www.endocrinology-journals.org 
GH and food intake, whereas cross-ApEn, a measure of asynchrony, was lower for $\mathrm{GH} /$ food intake than for ghrelin/food intake (Tolle et al. 2002). While correlations between circulating ghrelin levels and the daynight rhythm have been reported (Murakami et al. 2002), this slow diurnal variation of ghrelin takes place on a different time scale than that of GH oscillations (12 vs $3.3 \mathrm{~h}$ ). Thus, our central assumption in this study is that ghrelin only has a modulatory effect on the amplitude of GH pulses, but is not directly involved in the generation of the rhythm; this is experimentally supported by studies in both rat (Zizzari et al. 2005) and human (Nass et al. 2008), indicating that endogenous ghrelin modulates $\mathrm{GH}$-pulse amplitude without altering the basic pulsatile pattern of GH secretion.

In the present work, we used our previously developed core model for the generation of the $\mathrm{GH}$ rhythm and extend it in order to include the actions of ghrelin at both central and peripheral sites. As has been shown by Tannenbaum et al. (2003) i.c.v. injection of ghrelin elicited a strong GH pulse in the circulation when administered during the spontaneous $\mathrm{GH}$ peak period; however, if the first pulse is followed by a second i.c.v. ghrelin injection $2 \mathrm{~h}$ later, the associated second $\mathrm{GH}$ pulse is always suppressed. In order to explain this behavior, we define three sites of action of ghrelin when injected i.c.v. First, ghrelin acts on the GHRHcontaining neurons in the hypothalamic arcuate (ARC) nucleus; second, it stimulates the release of neuropeptide-Y (NPY) from NPY-containing neurons in the ARC, and third, ghrelin antagonizes the effect of SRIF at the level of the pituitary. By contrast, i.v. injection of ghrelin acts at the level of the pituitary by binding to its receptor on somatotroph cells where it synergistically (in combination with GHRH) increases the release of GH and antagonizes the effect of SRIF. Moreover, i.v. ghrelin signals via the vagus nerve to the brain where it triggers the release of GHRH and contributes to the activation of the food intake signaling cascade (Date et al. 2002). Owing to GHRH release via the vagus nerve pathway following peripheral ghrelin injection, GHRH is also present at the pituitary during the trough phase of GH. Therefore, i.v. application of ghrelin during a secretion period as well as during a trough period elicits a GH pulse in the circulation (Tannenbaum et al. 2003).

The introduction of distinct sites of action of ghrelin administered either centrally or peripherally follows the concept proposed earlier (Bowers 2005, Sato et al. 2005) that gastric and hypothalamic ghrelins are different functional components of the ghrelin system. Thus, compared with a previously suggested model (Farhy \& Veldhuis 2005), the major novel features of the present model are a) the role played by NPY, a powerful orexigenic hormone, which also stimulates the release of SRIF (Rettori et al. 1990), and b) the dissimilar functions of ghrelin in the hypothalamus and in the pituitary. Furthermore, the predictions of this model were experimentally tested and confirmed in the present report.

\section{Materials and methods}

\section{Basis of the model}

We first briefly outline our previous model of GH secretion with the difference that GHRH oscillations are no longer driven by a mathematical construct; rather, this rhythm is now generated by a self-sustained oscillator. This can be easily achieved by a negatively delayed feedback signal such that GHRH exerts control on its own release. This type of ultrashort loop feedback oscillation has recently been suggested for luteinizing hormone-releasing hormone (LHRH), where a metabolic product of LHRH directly regulates LHRH neural function (Roberts et al. 2007).

\section{Core model}

The core model of GH rhythmogenesis consists of three dynamic concentration variables GHRH, SRIF, and GH. A scheme of the model is displayed in Fig. 1. The release of GH into the circulation is governed in a positive fashion by GHRH, which can be blocked by SRIF. For all such actions, we use Hill type modifier functions with the parameters $n_{i}$ and th, $i$ characterizing the slope and the threshold of the transition. We define the modifier functions $f$ for upregulation and $g$ for downregulation as follows, where $x$ denotes the concentration of the relevant regulating species:

$$
\begin{aligned}
& f\left(x, n_{i}, x_{\mathrm{th}, i}\right)=\frac{x^{n_{i}}}{x^{n_{i}}+x_{\mathrm{th}, i}^{n_{i}}} \\
& g\left(x, n_{i}, x_{\mathrm{th}, i}\right)=\frac{x_{\mathrm{th}, i}^{n_{i}}}{x^{n_{i}}+x_{\mathrm{th}, i}^{n_{i}}}
\end{aligned}
$$

The time derivative of circulating $\mathrm{GH}$ can then be described by the following equation:

$$
\begin{aligned}
\frac{\mathrm{dGH}}{\mathrm{d} t}= & -k_{\mathrm{GH}, \mathrm{cl}} \mathrm{GH} \\
& +k_{\mathrm{GH}, \mathrm{r}} f\left(\mathrm{GHRH}, n_{1}, \mathrm{GHRH}_{\mathrm{th}, 1}\right) g\left(\mathrm{SRIF}, n_{2}, \mathrm{SRIF}_{\mathrm{th}, 2}\right)
\end{aligned}
$$

where the first term gives the clearance of $\mathrm{GH}$ in the circulating blood and the second the secretion of GH from the pituitary gland with the rate constants $k_{\mathrm{GH}, \mathrm{cl}}$ (Chapman et al. 1991) and $k_{\mathrm{GH}, \mathrm{r}}$ respectively. As already mentioned in our previous work (Wagner et al. 1998), the feedback of insulin-like growth factor-I is not included since it takes place on a longer time scale and therefore is not essential for the generation of the $3 \cdot 3 \mathrm{~h}$ rhythm of GH. 


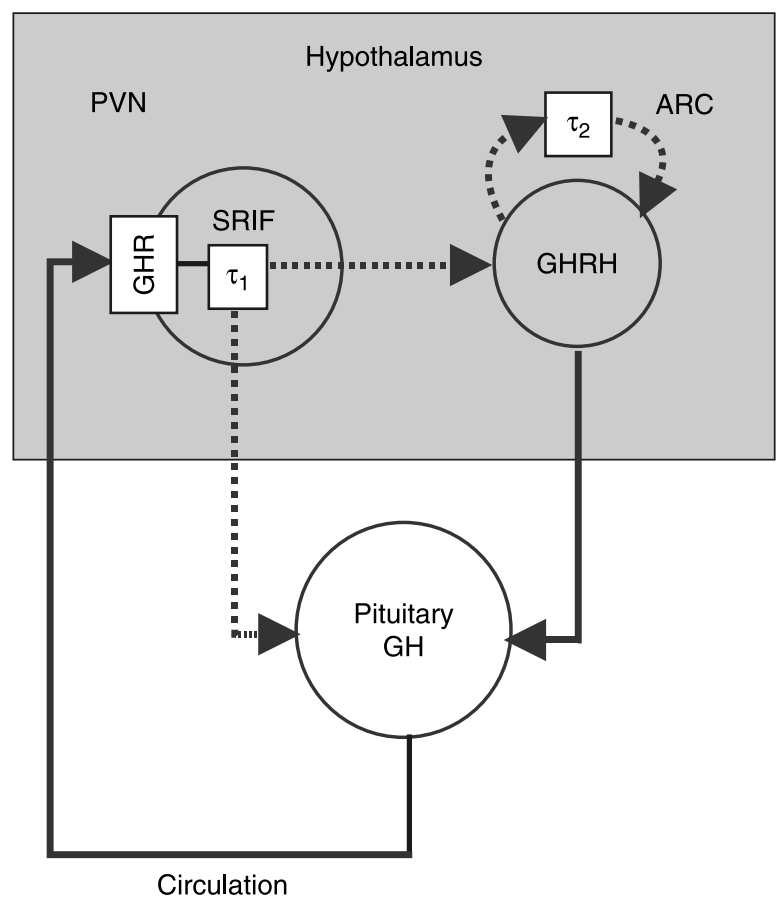

Figure 1 Scheme of the core model to generate the GH rhythm in the male and the female rat. It consists of a self-sustained $\sim 1 \mathrm{~h}$ rhythm of GHRH in the arcuate nucleus (ARC), which releases $\mathrm{GH}$ from pituitary somatotrophs into the circulation if somatostatin (SRIF) is low. The delayed release of SRIF is activated by the GH feedback signal via GH receptors (GHR) on SRIF neurons in the periventricular nucleus (PVN). The feedback of GH on its own release is delayed by $\tau_{1}$, whereas $\tau_{2}$ represents the latency of the GHRH feedback loop. A high SRIF level blocks the release of $\mathrm{GHRH}$ in the hypothalamus and also inhibits $\mathrm{GH}$ secretion at the pituitary. Dotted lines represent inhibitory signals and full lines show stimulating pathways.

\section{Ghrelin effects}

Although endogenous ghrelin affects the GH pulses, the observation discussed above of an approximately constant level of endogenous ghrelin (as compared with the altered levels resulting from experimental interventions) permits this modulation to be covered by ghrelin-dependent model parameters. For example, the rate constant for the release of $\mathrm{GH}$ may depend on the level of ghrelin, and this should be taken into account if we wish to investigate how the $\mathrm{GH}$ oscillations change when ghrelin is injected either centrally or systemically.

Two effects of ghrelin at the level of the pituitary have been established by experiments. First, it has been shown that somatotroph cells express the receptor GHS-R and that upon stimulation $\mathrm{Ca}^{2+}$ is released from internal stores and protein kinase $\mathrm{C}$ is activated (Cunha \& Mayo 2002). These two actions overlap with the effects of GHRH, and therefore activate the release of GH. Second, even during a trough phase, where SRIF is high, peripheral injection of ghrelin elicits a $\mathrm{GH}$ pulse (Tannenbaum et al. 2003). This GH response to ghrelin injection is delayed with a latency of about $5 \mathrm{~min}$. This means that first an interaction process between ghrelin and the SRIF-signaling pathway has to be activated before GH can be secreted. Furthermore, Tannenbaum et al. (2003) showed that GHRH must be present at the pituitary in order to facilitate the stimulating action of ghrelin on the release of GH. In our model, this is assured by the fact that both i.v. and i.c.v. injections of ghrelin lead to an increased secretion of GHRH.

In the simulations, the requirement for GHRH for GH release is also expressed by a Hill-type modifier function. If GHRH is below a given threshold, ghrelin's ability to release $\mathrm{GH}$ is abolished. On the other hand, if the level of GHRH is above the threshold ghrelin develops its full activity. Just recently, interactions between the ghrelin and the GHRH-signaling pathway have been observed. Casanueva et al. (2008) reported that the ghrelin GHS-R1a receptor can be activated by GHRH. Moreover, they discovered that GHRH appears to be an allosteric enhancer of ghrelin action. This allosteric modulation of the ghrelin-induced release of GH by GHRH is accounted for in our model by a Hill modifier function $f\left(\mathrm{GHRH}, n_{3}, \mathrm{GHRH}_{\mathrm{th}, 3}\right)$ in Eq. (3). To limit the releasing effect of ghrelin, a second modifier function is introduced. This leads to the following extended version of Eq. (2):

$$
\begin{aligned}
\frac{\mathrm{dGH}}{\mathrm{d} t}= & -k_{\mathrm{GH}, \mathrm{cl}} \mathrm{GH} \\
& +k_{\mathrm{GH}, \mathrm{r}} f\left(\mathrm{GHRH}, n_{1}, \mathrm{GHRH}_{\mathrm{th}, 1}\right) g\left(\mathrm{SRIF}, n_{2}, \mathrm{SRIF}_{\mathrm{th}, 2}\right) \\
& +k_{\mathrm{GH}, \mathrm{r}}^{\mathrm{GHS}} f\left(\mathrm{GHRH}, n_{3}, \mathrm{GHRH}_{\mathrm{th}, 3}\right) f\left(\mathrm{GHS}, n_{4}, \mathrm{GHS}_{\mathrm{th}, 4}\right)
\end{aligned}
$$

where GHS denotes the concentration of ghrelin in the pituitary and $k_{\mathrm{GH}, \mathrm{r}}^{\mathrm{GHS}}$ the associated release rate constant.

\section{Antagonism of SRIF}

The antagonizing effect of ghrelin on the inhibitory action of SRIF (Smith et al. 1996) is simulated by a ghrelin-dependent threshold of the SRIF block, which is affected by centrally and peripherally injected ghrelin:

$\mathrm{SRIF}_{\mathrm{th}, 2}=\mathrm{SRIF}_{\mathrm{th}, 02}+d \mathrm{th} \times f\left(\mathrm{GHS}, n_{5}, \mathrm{GHS}_{\mathrm{th}, 5}\right)$

where $d$ th denotes the maximal change of the SRIF threshold.

\section{GH feedback}

As is well known, GH feeds back via GH-R on SRIFcontaining neurons in the periventricular nucleus (PVN; Burton et al. 1992). It increases the release of SRIF, which in turn shuts down GH secretion from 
the pituitary into the circulation. This feedback signal is delayed by $\tau_{1} \approx 60 \mathrm{~min}$ and is finally responsible for the $3 \cdot 3 \mathrm{~h}$ rhythm in the male rat (Wagner et al. 1998). Owing to the dimerization of GH-R upon binding (Cunningham et al. 1991) the number of activated receptors follows a monotonically increasing function, which saturates for large $\mathrm{GH}$ values (Wagner et al. 1998). The concentration of activated GH-R, normalized by the total receptor quantity, turns out to be

$$
\mathrm{GHR}=\frac{\alpha}{(\alpha+1)^{2}} \frac{1}{16 \beta \mathrm{GH}}\left(\sqrt{1+8 \beta \mathrm{GH} \frac{\alpha+1}{\alpha}}-1\right)^{2}
$$

where $\alpha$ and $\beta$ are parameters that can be related to the binding process (Wagner et al. 1998). The time dependence of SRIF release then reads

$\frac{\mathrm{dSRIF}}{\mathrm{d} t}=-k_{\mathrm{SRIF,Cl}} \mathrm{SRIF}+k_{\mathrm{SRIF}, \mathrm{G}} \mathrm{GHR}\left(t-\tau_{1}\right)$

in which the clearance rate was taken from Farhy et al. (2007).

\section{GHRH oscillations}

The major assumption we have made in our previous paper is that GHRH is released in a $1 \mathrm{~h}$ rhythm into the portal blood (Wagner et al. 1998). It emerges that from a modeler's perspective, the way these oscillations are generated do not determine the GH rhythm in the circulation. In Wagner et al. (1998), we have used an intrinsic pulse generator that might be governed by inputs from neurons in the suprachiasmatic nucleus to produce the $1 \mathrm{~h}$ rhythm. However, the GHRH oscillations can also be generated by mutual interaction of GHRH neurons with SRIF neurons in the ARC (Farhy \& Veldhuis 2004). Here, we have shown a third possibility, based on recent findings with the LHRHcontaining neurons in the hypothalamus. Roberts $e t$ al. (2007) have recently reviewed the evidence that a metabolic product of LHRH feeds back on the release of LHRH. We use this idea to generate the GHRH rhythm directly by a delayed $\left(\tau_{2}\right)$, negative feedback of GHRH on its own release using a half life of GHRH suggested by Farhy et al. (2007)

$$
\begin{aligned}
\frac{\mathrm{dGHRH}}{\mathrm{d} t}=- & k_{\mathrm{GHRH}, \mathrm{cl}} \mathrm{GHRH} \\
+ & k_{\mathrm{GHRH}, \mathrm{r}} g\left(\mathrm{SRIF}, n_{6}, \mathrm{SRIF}_{\mathrm{th}, 6}\right) \\
& g\left(\mathrm{GHRH}\left(t-\tau_{2}\right), n_{7}, \mathrm{GHRH}_{\mathrm{th}, 7}\right)
\end{aligned}
$$

The inhibition of GHRH released by SRIF is represented by the downregulating modifier function $g$ (SRIF, $\left.n_{6}, \mathrm{SRIF}_{\mathrm{th}, 6}\right)$, whereas the modifier function controlling the release is $g\left(\mathrm{GHRH}\left(t-\tau_{2}\right), n_{7}\right.$,
$\left.\mathrm{GHRH}_{\mathrm{th}, 7}\right)$. In the hypothalamus, there is compelling evidence that ghrelin receptors are present on GHRHcontaining neurons in the ARC (Tannenbaum et al. 1998, 2003, Willesen et al. 1999). In analogy to the interaction between GHRH and ghrelin at the pituitary, we assume that the action of ghrelin on GHRH neurons in the hypothalamus primarily increases GHRH secretion and secondarily antagonizes the SRIF effect. However, if we assume a large threshold, the SRIFdependent release function remains in the linear regime and the primary action of ghrelin is accounted for by adding a further term to Eq. (7) reading:

$k_{\mathrm{GHRH}, \mathrm{r}}^{\mathrm{GHS}} \mathrm{GHS}_{\mathrm{cen}}$

Thus, in our model, central injection of ghrelin will always increase the release of GHRH, independent of the SRIF level. This simplified view is justified for the present simulations, although it is known that flooding the hypothalamus with SRIF prior to ghrelin application will abolish the ghrelin effect (Fairhall et al. 1995). This latter effect could easily be implemented using a SRIF threshold for the ghrelin-induced GHRH release.

\section{Ghrelin-NPY pathway}

The second set of cells in the ARC which contain ghrelin receptors are the NPY neurons. This has been shown by double-labeling experiments for GHS-R and NPY (Willesen et al. 1999, Tannenbaum et al. 2003), as well as by $c$-fos expression upon GHS activation in combination with NPY mRNA expression (Dickson \& Luckman 1997). Rettori et al. (1990) reported that the link between NPY and the suppression of GH in the circulation is mediated by a discharge of SRIF. Injections of NPY led to a suppression of GH lasting, after a delay of about 30-60 min, up to $2 \mathrm{~h}$. They further established a direct link between NPY axons and SRIF neurons by receptor analysis. In the goat, which seems to have a GH profile similar to the rat but with a periodicity of $\sim 5 \mathrm{~h}$, and the same effect of NPY administration was observed (Mogi et al. 2004). Moreover, Pierroz et al. (1996) have shown that chronic i.c.v. administration of NPY to rats for 5 days abolishes the release of GH completely. Therefore, we introduce a new variable for NPY, the release of which is elicited by ghrelin:

$\frac{\mathrm{dNPY}}{\mathrm{d} t}=-k_{\mathrm{NPY}, \mathrm{cl}} \mathrm{NPY}+k_{\mathrm{NPY}, \mathrm{r}} \mathrm{GHS}_{\mathrm{cen}}$

A clearance term for NPY is incorporated. In human, the half life of NPY was reported to be in the range of a few minutes (Grouzmann et al. 2001) so we selected a rate of $1 / \mathrm{min}$ to simulate the rat NPY elimination. Owing to the NPY-induced SRIF discharge, the following expression has then to be added to Eq. (6): 
$k_{\mathrm{SRIF}, \mathrm{r}}^{\mathrm{NPY}} \mathrm{NPY}\left(t-\tau_{3}\right)$

The delay accounts for the fact that GH is suppressed for as long as $2 \mathrm{~h}$ after NPY administration. Therefore, the sum of $\tau_{1}$ and $\tau_{3}$ is about $120 \mathrm{~min}$. Here, we selected $\tau_{3}$ to be $60 \mathrm{~min}$.

\section{Ghrelin-blood-brain barrier}

A further consideration in understanding the simulations (and also the experiments) is the direction of ghrelin transport across the blood-brain barrier. As Banks et al. (2002) reported, the transport of ghrelin across this barrier seems to be a highly regulated process. In mice, they observed a minimal mouse-ghrelin (m-ghrelin) influx and a rapidly saturating humanghrelin (h-ghrelin) inflow to the brain. By contrast, the brain to blood efflux of m-ghrelin and h-ghrelin occurred at a similar rate with a time constant of $\sim 10 \mathrm{~min}$.

\section{Vagus nerve pathway}

There is increasing evidence that the peripheral ghrelin signal is mediated to the brain via the vagus nerve, rather than by crossing the blood-brain barrier. In patients with a dissected vagus nerve, i.v. injection of ghrelin does not increase food intake but it still causes a rise in GH release (le Roux et al. 2005). Moreover, Date et al. (2002) convincingly showed that vagotomy in the rat abolishes the food intake signal, and $c$-fos expression in neurons of the ARC is blunted. This suggests that the ghrelin signals to the pituitary and to the brain go by different pathways. The vagus nerve ends in the brain stem and the signal is not further conveyed via ghrelin. Therefore, ghrelin receptors on neurons in the ARC are not the target of this signal, although NPY and agouti-related protein (AGRP) containing neurons in the ARC are activated upon i.v. ghrelin injection (Dickson \& Luckman 1997). We assume that this latter set of neurons is activated by the afferents of the vagus nerve mediating the orexigenic effect of ghrelin. To express the NPY activation by peripheral ghrelin, we add the following term to Eq. (8):

$k_{\mathrm{NPY}, \mathrm{r}}^{\mathrm{vgn}} \mathrm{GHS}_{\mathrm{per}}$

Finally, we have to account for the effect of peripheral ghrelin on the release of GHRH via the vagus nerve. Since this signal is not mediated via ghrelin receptors on GHRH neurons, it is assumed to be independent of SRIF. Thus, i.v. injection of ghrelin elicits a pulse of GHRH into the portal blood. In order to mimic this effect, the following term is introduced into Eq. (7):

$k_{\mathrm{GHRH}, \mathrm{r}}^{\mathrm{vgn}} f\left(\mathrm{GHS}_{\mathrm{per}}, n_{8}, \mathrm{GHS}_{\mathrm{th}, 8}\right)$

Here, we assume that the signal that reaches the GHRH neurons is proportional to the ghrelin level in the circulation. All proportionality constants are then combined in $k_{\mathrm{GHRH}, \mathrm{r}}^{\mathrm{vgn}}$.

\section{Description of the model}

The entire system reduces to a single compact model obeying the following four equations (that include a small basal rate of GHRH release):

$$
\begin{aligned}
& \frac{\mathrm{dSRIF}}{\mathrm{d} t}= \\
& -k_{\mathrm{SRIF}, \mathrm{cl}} \mathrm{SRIF}+k_{\mathrm{SRIF}, \mathrm{r}} \operatorname{GHR}\left(t-\tau_{1}\right)+k_{\mathrm{SRIF}, \mathrm{N}}^{\mathrm{NPY}} \mathrm{NPY}\left(t-\tau_{3}\right) \\
& \frac{\mathrm{dNPY}}{\mathrm{d} t}= \\
& -k_{\mathrm{NPY}, \mathrm{cl}} \mathrm{NPY}+k_{\mathrm{NPY}, \mathrm{r}} \mathrm{GHS}_{\mathrm{cen}}+k_{\mathrm{NPY}, \mathrm{r}}^{\mathrm{vgn}} \mathrm{GHS}_{\mathrm{per}} \\
& \frac{\mathrm{dGHRH}}{\mathrm{d} t}= \\
& -k_{\mathrm{GHRH}, \mathrm{cl}} \mathrm{GHRH}+k_{\mathrm{GHRH}, \mathrm{r}} g\left(\mathrm{SRIF}, n_{6}, \mathrm{SRIF}_{\mathrm{th}, 6}\right) \\
& g\left(\mathrm{GHRH}\left(t-\tau_{2}\right), n_{7}, \mathrm{GHRH}_{\mathrm{th}, 7}\right)+k_{\mathrm{GHRH}, \mathrm{r}}^{\mathrm{GHS}} \mathrm{GHS}_{\mathrm{cen}} \\
& +k_{\mathrm{GHRH}, \mathrm{r}}^{\mathrm{vgn}} f\left(\mathrm{GHS}_{\mathrm{per}}, n_{8}, \mathrm{GHS}_{\mathrm{th}, 8}\right)+\text { basal } \\
& \frac{\mathrm{dGH}}{\mathrm{d} t}= \\
& -k_{\mathrm{GH}, \mathrm{cl}} \mathrm{GH}+k_{\mathrm{GH}, \mathrm{r}} f\left(\mathrm{GHRH}, n_{1}, \mathrm{GHRH}_{\mathrm{th}, 1}\right) \\
& g\left(\mathrm{SRIF}, n_{2}, \mathrm{SRIF}_{\mathrm{th}, 2}\right)+k_{\mathrm{GH}, \mathrm{r}}^{\mathrm{GHS}} f\left(\mathrm{GHRH}, n_{3}, \mathrm{GHRH}_{\mathrm{th}, 3}\right) \\
& f\left(\mathrm{GHS}, n_{4}, \mathrm{GHS}_{\mathrm{th}, 4}\right)
\end{aligned}
$$

The injections of ghrelin were simulated using a constant injection rate $\left(\mathrm{GHS}_{\text {i.v. }}=0.5 \mu \mathrm{g} / \mathrm{ml}\right.$ for $5 \mathrm{~min}$; $\mathrm{GHS}_{\text {i.c.v. }}=0.5 \mathrm{ng} / \mathrm{ml}$ for $5 \mathrm{~min}$ ) and a single clearance term with an elimination rate determined by Akamizu et al. (2004).

$$
\begin{aligned}
& \frac{\mathrm{dGHS}_{\mathrm{cen}}}{\mathrm{d} t}=-k_{\mathrm{GHS}, \mathrm{cl}} \mathrm{GHS}_{\mathrm{cen}}+k_{\mathrm{GHS}, \mathrm{r}} \mathrm{GHS}_{\mathrm{i} . c . v .} \\
& \frac{\mathrm{dGHS}_{\mathrm{per}}}{\mathrm{d} t}=-k_{\mathrm{GHS}, \mathrm{cl}} \mathrm{GHS}_{\mathrm{per}}+k_{\mathrm{GHS}, \mathrm{r}} \mathrm{GHS}_{\mathrm{i} . v .}
\end{aligned}
$$

Furthermore, we assume different dilutions for i.v.and i.c.v.-injected ghrelin at the level of the pituitary. The dilutions of the injected ghrelin concentrations are generally absorbed in the rate constants and thresholds and therefore do not appear in the equations. However, if both injections have a common site of action, we have to account for this effect. Hence, we introduce a parameter dil that represents the ratio of 
dilutions. The active concentration at the pituitary, which enters the differential equation for GH in Eq. (9), then reads:

$\mathrm{GHS}=\mathrm{GHS}_{\mathrm{per}}+d i l \times \mathrm{GHS}_{\mathrm{cen}}$

The set of rate constants used is shown in Table 1 and the thresholds and Hill coefficients are presented in Table 2. As we have already shown, the male GH profile can be changed into the female rhythm by altering the feedback strength given by the two parameters of the GH binding curve $\alpha$ and $\beta$ (Wagner et al. 1998). These parameters together with the delays are shown in Table 3. The parameters $\alpha, \beta$, and $\tau_{1}$ were already estimated in Wagner et al. (1998). The time delay $\tau_{2}$ determining the period of the GHRH oscillations was estimated as $24.5 \mathrm{~min}$ and $\tau_{3}$ as $60 \mathrm{~min}$ in order to achieve the $2 \mathrm{~h}$ effect of NPY-induced SRIF. The remaining parameters were adjusted to reproduce the experimental data. The integration was performed using a fourth order Runge-Kutta algorithm and programmed in Matlab 7 (Mathworks, Brantford, Ontario, Canada).

\section{Experimental test of the model}

\section{Animals and experimental procedure}

Adult male Sprague-Dawley rats (200-235 g), purchased from Charles River Canada (St Constant, Canada) were individually housed on a $12 \mathrm{~h}$ light: $12 \mathrm{~h}$ darkness cycle (lights on, 0600-1800 h) in a temperature $\left(22 \pm 1{ }^{\circ} \mathrm{C}\right)$ - and humidity-controlled room. Purina rat chow (Ralston Purina, St Louis, MO, USA) and tap water were available ad libitum.

Chronic i.c.v. and i.v. cannulae were implanted under sodium pentobarbitol $(50 \mathrm{mg} / \mathrm{kg}$, i.p.) anesthesia using previously described techniques (Tannenbaum et al. 2003). The placement of the i.c.v. cannula was verified by both a positive drinking response to carbachol

Table 1 Set of rate constants used in the simulation

Release rate constants

\begin{tabular}{llll}
\multicolumn{2}{l}{ Clearance rate constants } & & \\
$k_{\mathrm{SRIF}, \mathrm{cl}}$ & $0 \cdot 5 / \mathrm{min}$ & $k_{\mathrm{SRIF}, \mathrm{r}}$ & $150 / \mathrm{min}$ \\
$k_{\mathrm{NPY}, \mathrm{cl}}$ & $1 / \mathrm{min}$ & $k_{\mathrm{NPY}, \mathrm{r}}$ & $1 / \mathrm{min}$ \\
$k_{\mathrm{GHRH}, \mathrm{cl}}$ & $0 \cdot 7 / \mathrm{min}$ & $k_{\mathrm{GHRH}, \mathrm{r}}$ & $800 \mathrm{pg} / \mathrm{ml}$ per min \\
$k_{\mathrm{GH}, \mathrm{cl}}$ & $0 \cdot 08 / \mathrm{min}$ & $k_{\mathrm{GH}, \mathrm{r}}$ & $300 \mathrm{ng} / \mathrm{ml}$ per min \\
$k_{\mathrm{GHS}, \mathrm{cl}}$ & $0 \cdot 08 / \mathrm{min}$ & $k_{\mathrm{GHS}, \mathrm{r}}$ & $150 / \mathrm{min}$ \\
& & $k_{\mathrm{SRIF}, \mathrm{r}}^{\mathrm{NPY}}$ & $400 / \mathrm{min}$ \\
& $k_{\mathrm{GHRH}, \mathrm{r}}^{\mathrm{GHS}}$ & $3000 / \mathrm{min}$ \\
& $k_{\mathrm{GH}, \mathrm{r}}^{\mathrm{GHS}}$ & $100 \mathrm{ng} / \mathrm{ml}$ per min \\
& & $k_{\mathrm{GHRH}, \mathrm{r}}^{\mathrm{vgn}}$ & $500 \mathrm{pg} / \mathrm{ml}$ per min \\
& & $k_{\mathrm{NPY}, \mathrm{r}}^{\mathrm{vgn}}$ & $0.0008 / \mathrm{min}$
\end{tabular}

$(100 \mathrm{ng} / 10 \mu \mathrm{l})$ i.c.v. injection on the day after surgery and methylene blue dye at the time of death. After surgery, the rats were placed directly in isolation test chambers with food and $\mathrm{H}_{2} \mathrm{O}$ freely available until body weight returned to preoperative levels (usually within 5-7 days). During this time, the rats were handled daily to minimize any stress associated with handling on the day of the experiment. On the test day, food was removed $1.5 \mathrm{~h}$ before the start of sampling and was returned at the end.

We examined the temporal pattern and magnitude of the GH response to ghrelin, administered either centrally or peripherally in an alternating sequence. One group of free-moving rats was injected with ghrelin i.v. $(5 \mu \mathrm{g})$ at $1100 \mathrm{~h}$ and ghrelin i.c.v. $(500 \mathrm{ng})$ at $1300 \mathrm{~h}$; a second group received these same injections but in a reversed order, i.e. ghrelin i.c.v. at $1100 \mathrm{~h}$ and i.v. at $1300 \mathrm{~h}$. The times of 1100 and $1300 \mathrm{~h}$ were chosen since these times reflect typical peak and trough periods of GH secretion, as previously documented (Tannenbaum \& Martin 1976, Tannenbaum \& Ling 1984). The human ghrelin peptide (Phoenix Pharmaceuticals, Belmont, CA, USA) had been diluted in normal saline just before use. Blood samples $(0.3 \mathrm{ml})$ were withdrawn every $15 \mathrm{~min}$ over a $6 \mathrm{~h}$ sampling period $(1000-1600 \mathrm{~h})$ from all animals. To document the rapidity of the GH response to ghrelin, an additional blood sample was obtained $5 \mathrm{~min}$ after each injection of the peptide. All blood samples were immediately centrifuged, and the plasma was separated and stored at $-20^{\circ} \mathrm{C}$ for subsequent assay of GH. To avoid hemodynamic disturbance, the red blood cells were resuspended in normal saline and returned to the animal after removal of the next blood sample.

All animal-based procedures were approved by the McGill University Animal Care Committee in compliance with the guidelines of the Canadian Council on Animal Care.

\section{GH assay}

Plasma GH concentrations were measured in duplicate by double antibody RIA using materials supplied by the NIDDK Hormone Distribution Program (Bethesda, MD, USA). The averaged plasma GH values were reported in terms of the rat $\mathrm{GH}$ reference preparation (rGH RP-2). The standard curve was linear between 0.62 and $160 \mathrm{ng} / \mathrm{ml}$; the least detectable concentration of plasma GH under the conditions used was $1 \cdot 2 \mathrm{ng} / \mathrm{ml}$. All samples with values above $160 \mathrm{ng} / \mathrm{ml}$ were reassayed at dilutions ranging from 1:2 to 1:10. The intra- and interassay coefficients of variation were $7 \cdot 7$ and $10.7 \%$ respectively, for duplicate samples of pooled plasma containing a mean $\mathrm{GH}$ concentration of $60 \cdot 7 \mathrm{ng} / \mathrm{ml}$. 
Table 2 Set of thresholds and Hill coefficients (GH-secretagogue (GHS) denotes ghrelin)

\section{Hill coefficient}

\section{Threshold}

$\mathrm{GHRH}_{\text {th } 1}$

$\mathrm{SRIF}_{\text {th,2(02) }}$

$\mathrm{GHRH}_{\text {th,3 }}$

$\mathrm{S}_{\mathrm{th}, 4}$

$\mathrm{GHS}_{\mathrm{th}, 5}$

$\mathrm{SRIF}_{\text {th,6 }}$

$\mathrm{GHRH}_{\text {th,7 }}$

$\mathrm{GHS}_{\mathrm{th}, 8}$

Description

\section{Statistical analyses}

Student's $t$-tests for paired and unpaired data, as appropriate, were used for statistical comparisons within and between experimental groups. The integrated area under the GH response curve (AUC) was calculated by the linear trapezoidal method. The results are expressed as the mean \pm s.E.M. $P<0.05$ was considered significant.

\section{Results}

\section{Simulations and comparisons with experiments}

\section{Stability of the model}

The core model of GH oscillations is shown in Fig. 1 and described by Eqs (2), (6), and (7). It is obtained from the full model by eliminating ghrelin effects. We first studied the stability of the GH oscillations by varying the time delays $\tau_{1}$ (GH feedback) and $\tau_{2}$ (GHRH delay loop). The plane spanned by $\tau_{1}$ and $\tau_{2}$ can be divided into three different zones (see Fig. 2B). Stable double-peak oscillations are observed in zone 2, whereas irregular oscillatory behavior is obtained in zones 1 and 3 . If one moves vertically within zone 2 by increasing the delay $\tau_{2}$, the double peak starts with a pulse of small amplitude followed by a large one. Further augmenting $\tau_{2}$ leads to a double pulse of equal amplitudes, whereas close to the border with zone 1 the usual amplitude sequence appears with a large first pulse and a reduced second one. Representative GH profiles for $\tau_{1}=60 \mathrm{~min}$ and $\tau_{2}=18 \mathrm{~min}$ (zone 3), 21, 23.5, 24.5 min (zone 2), and $26 \mathrm{~min}$ (zone 1) are presented in the right-hand panel of Fig. 2. As expected, the period of the oscillations changes with increasing time delays. This relationship is presented in Fig. 2A for delays along the borderline between zones 2 and 1 . These results led us to simulate the core model with $\tau_{1}=60 \mathrm{~min}$ and $\tau_{2}=24.5 \mathrm{~min}$, producing a periodicity of $\sim 200 \mathrm{~min}$. With fixed time delays other parameters may undergo large variations without altering the timing of the secretion episodes. For example, the rate constant for the release of $\mathrm{GH}$ into the circulation, $k_{\mathrm{GH}, \mathrm{r}}$, could be changed in the range $150<250$ $<1500 \mathrm{ng} / \mathrm{ml}$ resulting only in an amplitude variation of the GH profile (the first peak varied between $145<213<670 \mathrm{ng} / \mathrm{ml})$. With the fixed parameter set, we also studied the transients due to different initial conditions of SRIF, GHRH, and GH. We scanned the concentrations in the range of $0 \leq \mathrm{SRIF} \leq 500 \mathrm{pg} / \mathrm{ml}$ (every $100 \mathrm{pg} / \mathrm{ml}$ ), $0 \leq \mathrm{GHRH} \leq 3000 \mathrm{pg} / \mathrm{ml}$ (every $500 \mathrm{pg} / \mathrm{ml}$ ), and $0 \leq \mathrm{GH} \leq 1000 \mathrm{ng} / \mathrm{ml}$ (every $200 \mathrm{ng} / \mathrm{ml}$ ) and observed that all transients converged to the regular GH profile within 500-1500 min. Owing to the limited amount of substance in an injection, the clearance rate, and the time course of NPY, peripherally and centrally applied ghrelin tend to 0 with time. They just perturb the core system; however, the concentrations of SRIF, GHRH, and GH never exceed the levels we have tested as initial conditions mentioned above. This provides numerical evidence that the system relaxes to stable oscillations after peripheral or central injections of ghrelin.

Table 3 The binding parameters for GH binding on somatostatin (SRIF) neurons

\begin{tabular}{lll}
\hline$\alpha$ & $4 \times 10^{-4}$ & Parameters that govern the binding of GH in the brain: Eq. (5) \\
$\beta$ & $1 \times 10^{-5}$ & \\
$\tau_{1}$ & $60 \mathrm{~min}$ & Time delay of GH on the release of SRIF: Eq. (6) \\
$\tau_{2}$ & $25 \mathrm{~min}$ & Time delay of GHRH on its own release: Eq. (7) \\
$\tau_{3}$ & $60 \mathrm{~min}$ & Time delay of NPY-induced SRIF release: Eq. (9) \\
$d \mathrm{th}$ & $150 \mathrm{ng} / \mathrm{ml}$ & Maximal change of SRIF threshold: Eq. (4) \\
dil & 10 & Dilution factor of centrally injected GHS at the pituitary: Eq. (11) \\
basal & $10 \mathrm{pg} / \mathrm{ml}$ per min & Basal GHRH release: Eq. (9) \\
\hline
\end{tabular}

The quantities $\alpha$ and $\beta$ determine the feedback strength. The table also displays the remaining parameters of the system (GHS denotes ghrelin). 

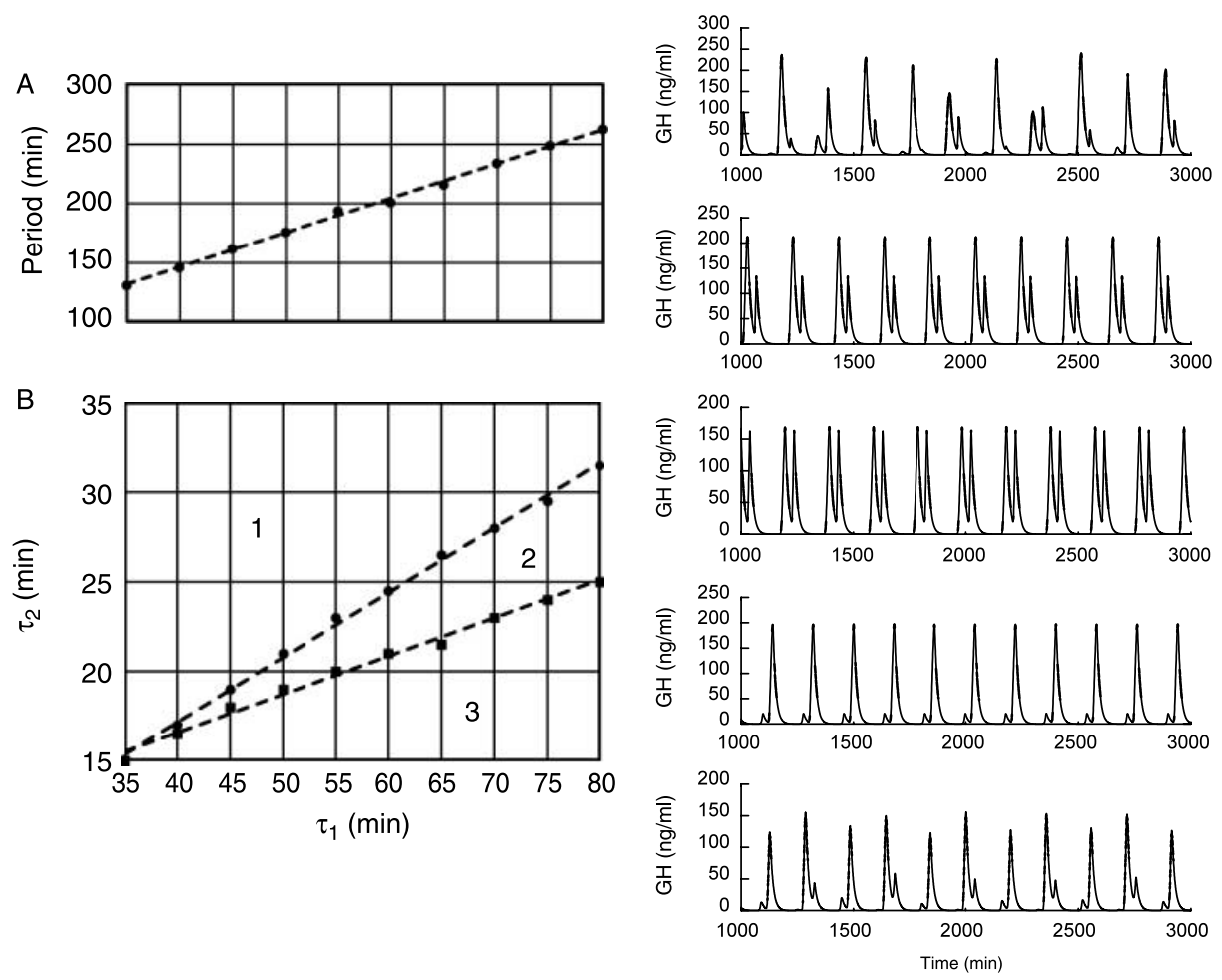

Figure 2 Stability of the core model. Left-hand panel: the zone of stable GH oscillations (zone 2) defined by the GH feedback delay $\tau_{1}$ and the delay of the GHRH generator $\tau_{2}$. (A) The period of the stable oscillations in zone 2 , with $\tau_{2}$ adjusted to be close to the borderline with zone 1 , as a function of $\tau_{1}$. (B) Zones of different oscillatory behavior. Irregular GH secretion events are obtained in zones 1 and 3. Right-hand panel: GH profiles moving along a vertical line in (B) with $\tau_{1}=60$ min and variable $\tau_{2}$ (from top to bottom $\tau_{2}=26 \mathrm{~min}, 24 \cdot 5,23 \cdot 5,21$, and $18 \mathrm{~min}$ ).

\section{Central injections of ghrelin}

The first set of simulations is devoted to the interpretation of i.c.v. injections of ghrelin in the male rat. The interactions associated with these experiments in our model are displayed in Fig. 3, and a comparison of simulations and experimentally derived results (Tannenbaum et al. 2003) are shown in Fig. 4. Taking into consideration the endogenous rhythm, different time points of ghrelin application are considered. First, a pair of i.c.v. injections is applied at 1100 and $1300 \mathrm{~h}$ (Fig. 4A) where a peak period and a trough period are expected in the GH profile respectively (Tannenbaum \& Martin 1976, Tannenbaum \& Ling 1984). During the first injection, the SRIF level is assumed to be low, whereas it is high during the second part of the secretion episode (Wagner et al. 1998). The opposite sequence of SRIF concentrations is expected when ghrelin is injected at 1300 and $1500 \mathrm{~h}$ (Fig. 4B). Interestingly, in both experiments, the first ghrelin injection elicited a large surge of GH in the circulation, whereas the second GH pulse is suppressed (see Fig. 4). This excludes the possibility that the normal endogenous SRIF level during the trough phase may be the reason for the suppression of the second pulse when the injections are applied at 1100 and $1300 \mathrm{~h}$.

The enhanced GH secretion compared with a regular pulse at $1100 \mathrm{~h}$ is the result of the increased GHRH release owing to the ghrelin injection, since SRIF is assumed to be low (Fig. 4A). However, the same pulse of ghrelin also stimulates the release of NPY with a delay of $60 \mathrm{~min}$. Furthermore, ghrelin affects the SRIF threshold at the pituitary via the brain-blood efflux (shown as an elevated dashed line in the SRIF panel of Fig. 4A). The latter two effects do not influence the actual GH pulse, but as we shall see, they influence the result of the second injection. Ghrelin administration at $1300 \mathrm{~h}$ leads again to an increased GHRH peak amplitude and a shifted SRIF threshold. If we consider only these two effects, we would again expect a large GH surge in the circulation. However, we have to take into account, in addition, the NPY pulse induced by the previous ghrelin injection. This further stimulates the release of SRIF and compensates for the elevated threshold, so that the secretion of GH from the pituitary remains almost blocked and only a minor pulse can be detected in the circulation (Fig. 4A). 


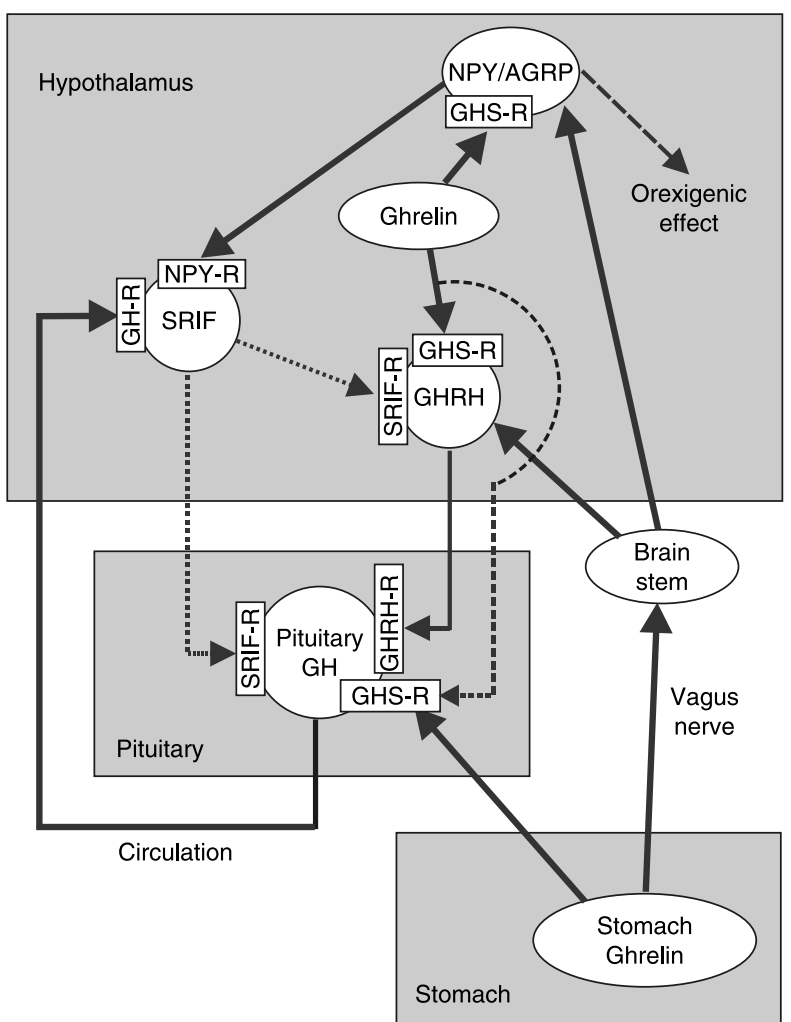

Figure 3 Scheme of the refined model including putative ghrelinsignaling pathways. Stimulating pathways are represented by strong, full lines whereas dotted lines show inhibitory routes. Stomach-derived ghrelin conveys a signal via the circulation to the pituitary (GH release action) and via the vagus nerve to the hypothalamus (GHRH and NPY release). Ghrelin in the hypothalamus stimulates GHRH and NPY neurons via ghrelin receptors (GHS-R) and also influences the SRIF block at the pituitary (increased GH release) via brain-blood efflux (small dashed line). In addition, NPY/AGRP-containing neurons, which mediate the orexigenic action, are activated (large dashed line).

A different picture appears when the first injection of ghrelin is applied at $1300 \mathrm{~h}$ (Fig. 4B). Here, we expect a high level of SRIF so that a simple augmentation of the GHRH peak amplitude would not be sufficient to induce a GH pulse in the circulation. Hence, there must be a signal from the hypothalamus to the pituitary that attenuates the SRIF effect. This can be modeled in different ways. As early as 1991, Bowers et al. (1991) had postulated the presence of an unknown hypothalamic factor (U-factor) which might be involved in stimulating GH secretion from the pituitary upon GHS application. Although introducing the U-factor would be one possibility, we successfully simulated i.c.v. injection by assuming that ghrelin reaches the pituitary via brain-blood efflux where it raises the SRIF threshold (but does not stimulate the vagus nerve since the ghrelin concentration is so low due to dilution). This allows one to simulate the antagonizing effect of ghrelin on SRIF at the pituitary on a phenomenological level (no molecular mechanisms are known so far). Owing to this shift, SRIF is below the threshold and together with the amplified GHRH pulse a large $\mathrm{GH}$ surge results in the circulation. Using the same arguments as above the NPY-SRIF pathway triggered by the first injection suppresses the second $\mathrm{GH}$ pulse (Fig. 4B).

\section{Peripheral injections of ghrelin}

The relevant sites of ghrelin action in the case of i.v. injections are seen in Fig. 3 and the simulations together with experimental GH profiles (Tannenbaum et al. 2003) are shown in Fig. 5. At the pituitary, peripheral ghrelin acts by binding to its receptor. It antagonizes the SRIF block and promotes the release of $\mathrm{GH}$ in the presence of GHRH. Ghrelin signals are transferred to the brain via the vagus nerve. They mediate the orexigenic effect of systemic ghrelin by activating NPY neurons and they induce the secretion of GHRH. Since ghrelin antagonizes the effect of SRIF and has the capacity to release GHRH from hypothalamic cells, it is not surprising that both i.v. injections lead to a large surge of $\mathrm{GH}$ in the circulating blood (Fig. 5).

\section{Alternating injections of ghrelin}

A simulation that highlights the dissimilar effects of ghrelin applied either centrally or peripherally (shown in Fig. 6) allowed verification of certain aspects of our model. In this computer experiment, we alternated the site of ghrelin application in a hypothetical doubleinjection trial. In Fig. 6A, the first ghrelin pulse is applied i.c.v. at $1100 \mathrm{~h}$ and the second pulse i.v. at $1300 \mathrm{~h}$. Both ghrelin applications elicit a GH pulse in the circulation (although the second pulse is somewhat smaller) due to the fact that the i.v. ghrelin injection counteracts the elevated SRIF level at the pituitary. By contrast, if the order of ghrelin applications is inverted (i.v. 1100 h, i.c.v. 1300 h) as shown in Fig. 6B, the first i.v. application $(1100 \mathrm{~h})$ triggers, in addition to the $\mathrm{GH}$ peak, a supplementary SRIF release at $1300 \mathrm{~h}$ (via NPY), which in turn severely reduces the second GH pulse as compared with the previous case.

The effects of alternating injections of ghrelin, predicted by the model and verified by the experiment, are readily understood on examination of Fig. 6. As discussed above, ghrelin suppresses the SRIF block at the pituitary by raising its threshold (the dashed and dotted line in the top panels of Figs 4-6). The i.v. threshold time profile is quite different from the i.c.v. time profile, because of the different doses and time constants. As can be seen in all the experiments modeled, the i.c.v. time course of the threshold is a 

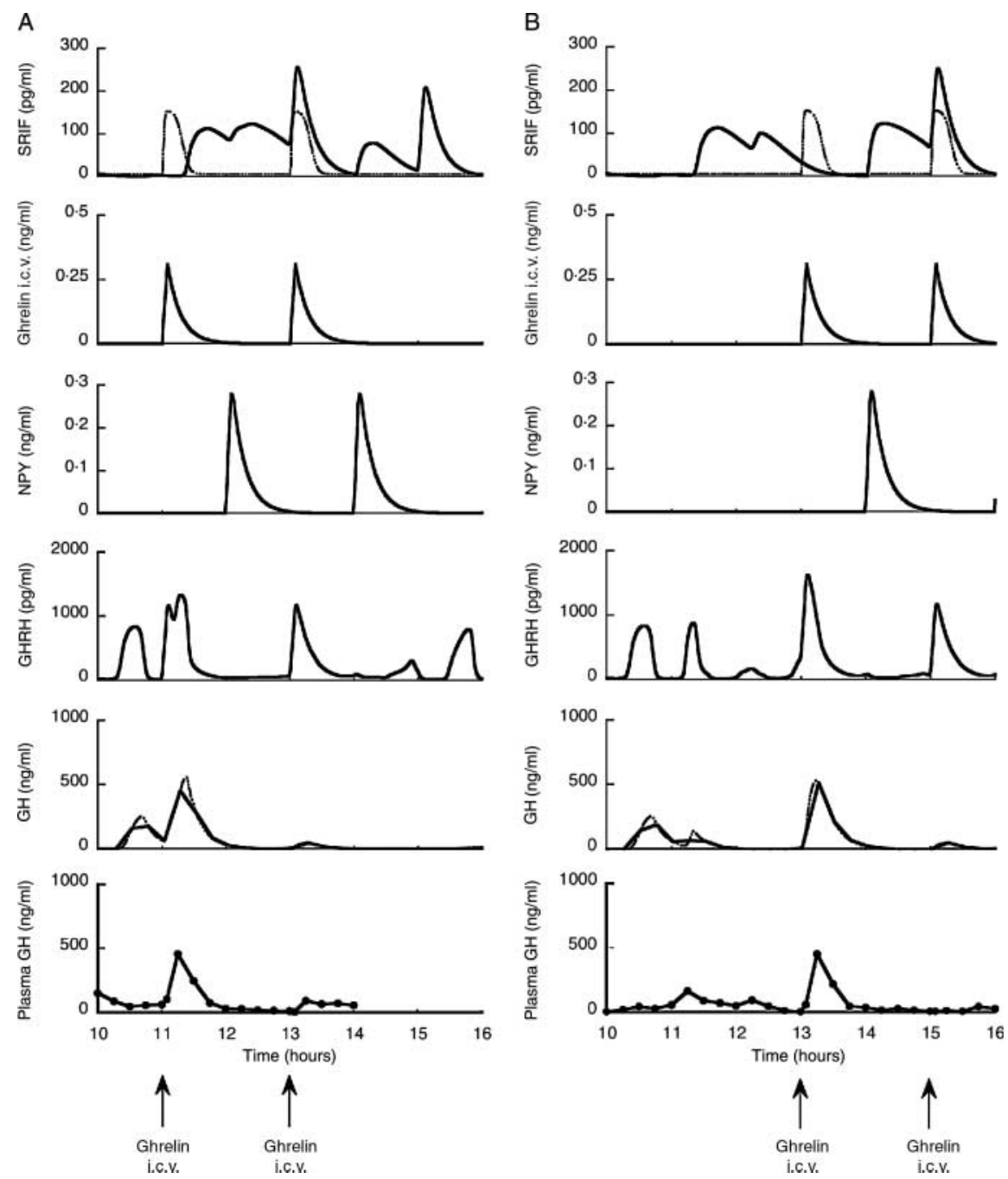

Figure 4 Simulation of the SRIF, centrally injected ghrelin, NPY, GHRH, and GH profiles upon i.c.v. injection of ghrelin at 1100 and $1300 \mathrm{~h}$ (in A) and at 1300 and $1500 \mathrm{~h}$ (in B) in the male rat. The shift of the SRIF threshold is shown in the SRIF versus time panel (dashed line). GH is shown as a continuous time course (dotted line) and as a 15 min sampled time course (full line). Lowest panel shows the experimental result (bold axes) of the averaged time course of GH from five different rats (Tannenbaum et al. 2003).

relatively short-lived peak. On the other hand, in the i.v. time course, the threshold rises rapidly to its maximal value and stays there for over an hour before dropping down. So in the i.c.v.-i.v. paradigm the i.v. ghrelin stimulates GHRH, while at the same time there is a steep rise in SRIF due to the NPY elicited by the i.c.v. ghrelin. But the effect of the SRIF peak is counteracted by the high SRIF threshold, which results in partial suppression of GH release. In the i.v.-i.c.v. paradigm, the events are similar but the peak in the SRIF threshold due to i.c.v. ghrelin falls to practically zero long before the SRIF peak itself has decayed, and hence the suppression of GH release is much greater.

\section{Verification of model predictions}

These predictions regarding the effects of inverting the sequence of i.v. and i.c.v. applications of ghrelin were experimentally corroborated in the present study. The temporal pattern of mean plasma GH responses to alternating ghrelin injections and the mean AUC over 45 min after each injection is shown in Fig. 7. In each case, there is a reduction in the mean GH level when the second injection is compared with the first but this reduction was far greater $(8 \cdot 5$-fold for the i.v.-i.c.v. paradigm versus $2 \cdot 4$-fold for i.c.v.-i.v.), and only reached significance $(P<0 \cdot 001)$ when i.c.v. followed i.v., as predicted by the model. 

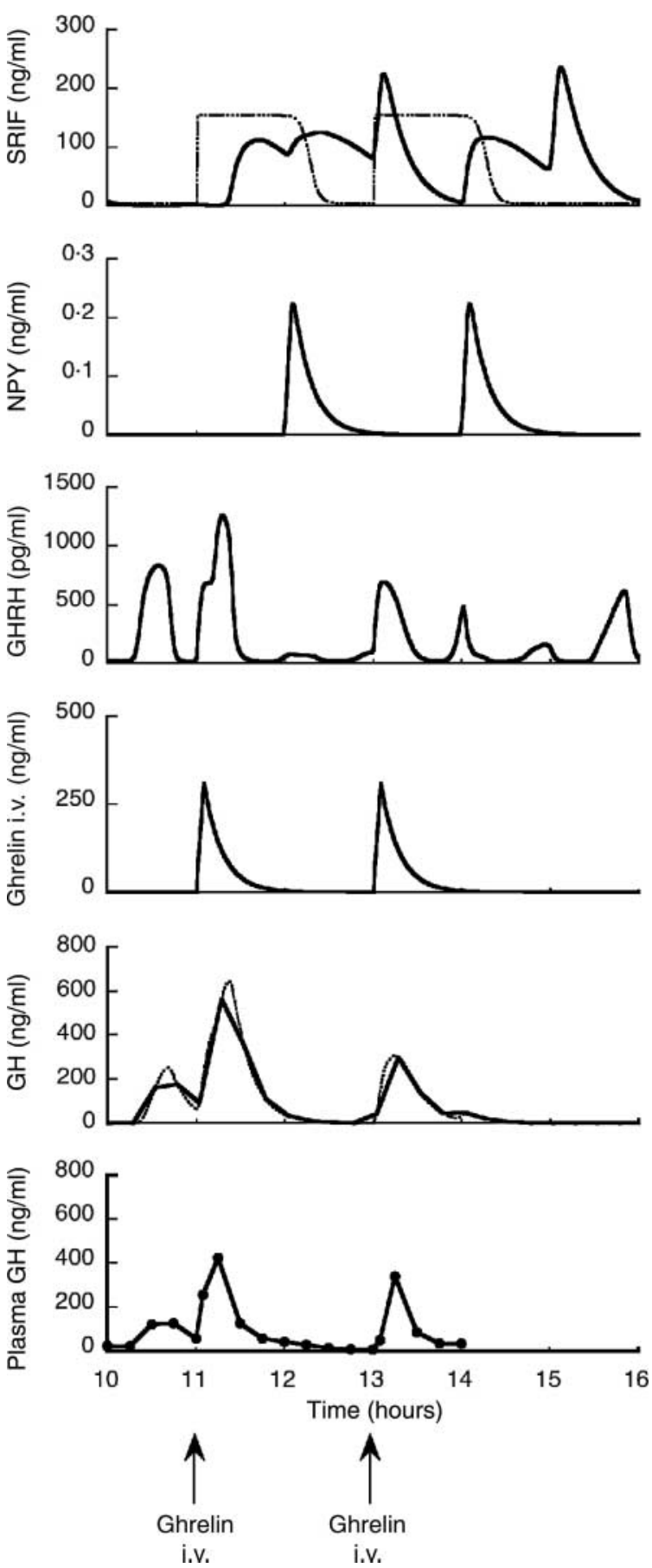

Figure 5 Simulation of the SRIF, NPY, GHRH, peripherally injected ghrelin, and GH profiles upon i.v. injection of ghrelin at 1100 and $1300 \mathrm{~h}$ in the male rat. The shift of the SRIF threshold is shown in the SRIF versus time panel (dashed line). GH is shown as a continuous time course (dotted line) and as a $15 \mathrm{~min}$ sampled time course (full line). The lowest panel shows the experimental result (bold axes) of the averaged time course of GH from five different rats (Tannenbaum et al. 2003).

\section{Discussion}

Pulsatility of GH secretion is essential for normal growth and therefore the study of GH oscillations is of physiological importance. Ghrelin is a powerful GHS and the first orexigenic hormone known that establishes a signaling pathway between the stomach and the brain. In humans, the ghrelin profile reveals a preprandial rise and a postprandial decline (Cummings et al. 2001); thereby implicating ghrelin as an important player in energy homeostasis. In this work, we studied the interaction between the ghrelin-signaling pathways and the GH neuroendocrine axis.

We first derived a new model of GH rhythmogenesis based on our previous work (Wagner et al. 1998). The scaffold of the model is a combination of two oscillators, the first of which is the feedback loop between SRIF and GH with constant GHRH input, the second is the GHRH oscillation. The modification introduced here is that the latter is now formed by a delay loop (rather than being a purely mathematical construct). This has two purposes: we wish to show that a) the rectangular shape of the GHRH profile used in our previous study is not required to obtain proper $\mathrm{GH}$ profiles and $\mathrm{b}$ ) the means by which the GHRH oscillations are generated are not of importance for the GH rhythm. If so, different possibilities of generating the GHRH oscillations lead to the same GH profile in the circulation. As we show in Fig. 2, the timing of the $\mathrm{GH}$ pulses is to a great extent determined by the delays $\tau_{1}$ and $\tau_{2}$. For a fixed ratio $\tau_{2} / \tau_{1} \approx 0 \cdot 4$, the shape of the GH profile is conserved but the periodicity rises from $130 \mathrm{~min}$ (for $\tau_{1}=35 \mathrm{~min}$ ) to $262 \mathrm{~min}$ (for $\tau_{1}=80 \mathrm{~min}$ ). At the borders of zone 2 (see Fig. 2), the two GH peaks essentially collapse to a single peak.

A major aspect of this work is to provide further insights into the GH neuroendocrine axis by studying perturbations of the system triggered by ghrelin injections. No clear experimental evidence of a ghrelin rhythm has been observed in the rat. In the work of Tolle et al. (2002), the small variation of ghrelin would be difficult to associate with oscillatory behavior (a day-night rhythm cannot be attributed to the measured profiles). Murakami et al. (2002) determined an apparent diurnal rhythm of ghrelin in the blood plasma, revealing peaks just before the light-on and light-off transitions. However, but for these two peaks, ghrelin is almost constant in these profiles. Therefore, it seems appropriate to approximate the level of ghrelin during the limited time period of interest (1000$1600 \mathrm{~h}$ ) as approximately constant in comparison with the perturbations applied. Some of the parameters in our model might depend on ghrelin on a longer time scale (days), but are not affected by the short time scale of the injections applied here. For example, the GH release rate $\left(k_{\mathrm{GH}, \mathrm{r}}\right)$ might change its value when ghrelin is chronically administered for several days. 

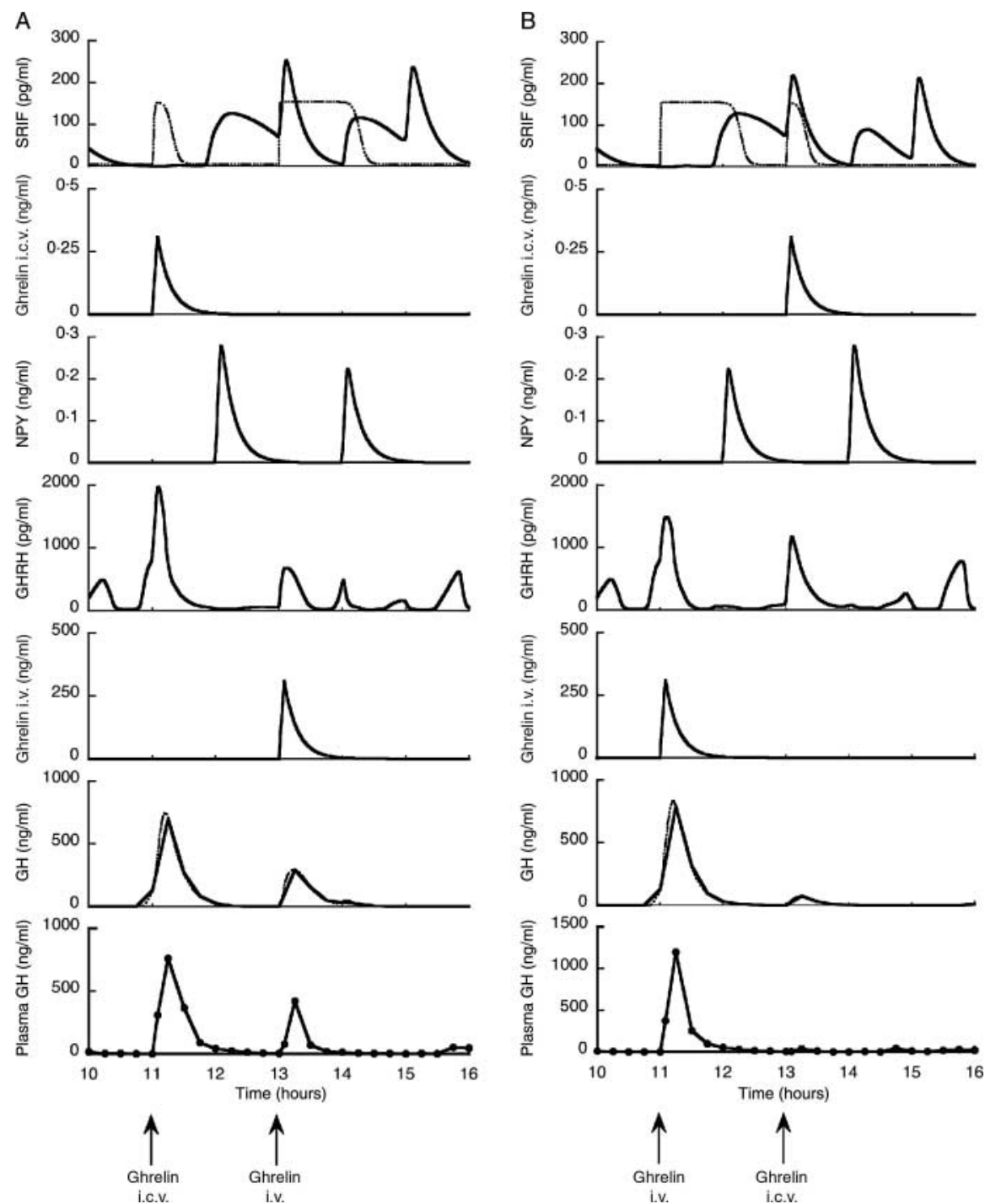

Figure 6 According to our model, changing the order of alternating ghrelin applications should lead to different $\mathrm{GH}$ profiles in the circulation. In $(\mathrm{A})$ the injection sequence changed from i.c.v. at $1100 \mathrm{~h}$ to i.v. at $1300 \mathrm{~h}$. Both applications result in a $\mathrm{GH}$ pulse, although the second pulse is lower. In (B), the sequence starts i.v. at $1100 \mathrm{~h}$ and ends i.c.v. at $1300 \mathrm{~h}$. In this case, the second $\mathrm{GH}$ pulse is significantly suppressed as compared with (A) owing to the NPY-induced SRIF peak at the pituitary. GH is shown as a continuous time course (dotted line) and as a 15 min sampled time course (full line). The lowest panel shows the experimental results (bold axes) of individual representative plasma $\mathrm{GH}$ profiles.

There are three possibilities that might account for the observed suppression in GH responsiveness to a second i.c.v. ghrelin injection administered 2 h later: a) ghrelin receptor downregulation or desensitization, b) an empty GHRH pool (that seems unlikely), and c) an additional signaling pathway. The ghrelin receptor GHS-R1a was cloned and identified in the pituitary and the hypothalamus (Howard et al. 1996). Considering that ghrelin signaling is mediated by this receptor, the reduced GH amplitude following the second i.c.v. injection (at $1300 \mathrm{~h}$ ) is apparently not explicable by receptor desensitization since at the pituitary both ghrelin signals (at 1100 and $1300 \mathrm{~h}$ ) are fully transmitted (Tannenbaum et al. 2003). The receptor downregulation observed by Camina et al. (2004) is inconsistent with these findings, possibly due to the experimental setup used. By contrast, Nogueiras et al. (2004) reported that GHS-R gene expression is upregulated in the ARC upon short-term treatment with ghrelin. We favor the third possibility since there is experimental evidence that the additional signaling pathway might be composed of NPY-containing 

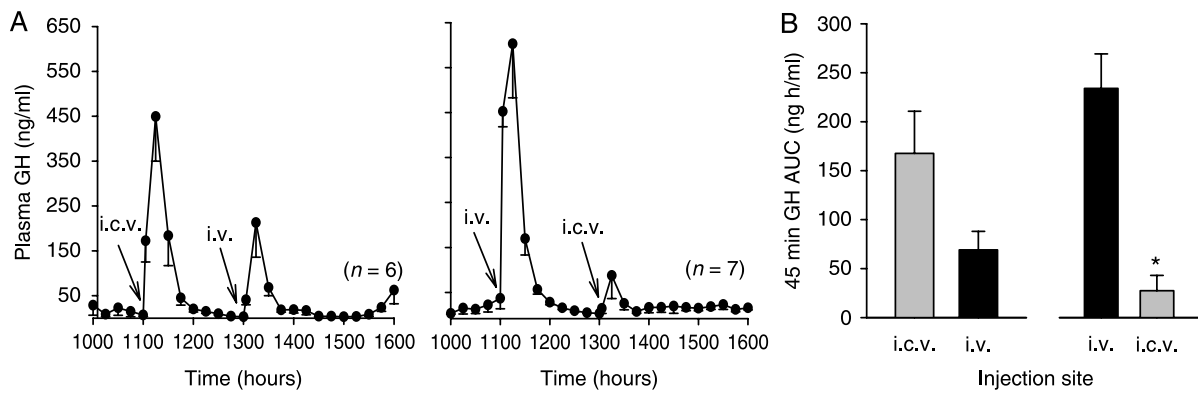

Figure 7 Averaged time course of plasma $\mathrm{GH}$ on changing the sequence of i.c.v. and i.v. ghrelin applications. In (A), the mean ( \pm S.E.M.) 6-h plasma GH profiles of both paradigms are given; in (B) bar graphs are presented showing the 45 min mean area under the GH response curve (AUC) following each ghrelin injection. Arrows indicate the times of i.c.v. and i.v. injections. Numbers of animals in each group are shown in parentheses. ${ }^{*} P<0.001$ compared with the first ghrelin injection given i.v.

neurons directing their axons to SRIF neurons in the PVN (Rettori et al. 1990) Additional lines of evidence for this pathway are given in White (1993) and Muller et al. (1999). Furthermore, the link between ghrelin and NPY has been made by co-localization studies of NPY-containing neurons and ghrelin receptors, which indeed overlap (Willesen et al. 1999, Tannenbaum et al. 2003).

In the hypothalamus, central ghrelin shifts the SRIF threshold at the pituitary and in concert with ghrelininduced GHRH activation it produces a GH secretion episode in the circulation. The shift of the SRIF threshold at the pituitary guarantees that a GH peak occurs in the circulation even during a trough phase. In addition to the GHRH release, NPY neurons are activated which in turn stimulate SRIF neurons and lead to a delayed SRIF increase at the pituitary. This additional SRIF surge is the reason why the threshold shift becomes ineffective during the second i.c.v. injection.

Our model predicts characteristic GH profiles with alternating peripheral and central injections of ghrelin. These predictions concerning the sequence of i.v. and i.c.v. applications of ghrelin were examined experimentally and confirmed in the present study. In both cases, the mean GH level was lower after the second injection. However, in accordance with the model, a significantly larger reduction was always seen when i.c.v. followed i.v.

Besides the well-established effects of ghrelin (antagonizing SRIF and inducing the release of $\mathrm{GH}$ ), the present model is based on the following principles a) short-term effects of i.v. ghrelin are twofold, firstly inducing $\mathrm{GH}$ release and antagonizing SRIF at the pituitary via ghrelin receptors, and secondly stimulating GHRH and NPY-SRIF secretion by activating afferents of the vagus nerve, and b) i.c.v. injection leads to a pulse of GHRH as well as NPY, which in turn stimulates a delayed surge of SRIF. If both the GHRH and
NPY-SRIF signals were to act simultaneously on somatotroph cells they would be contradictory. However, since the NPY-SRIF signal is delayed by about $2 \mathrm{~h}$, suppressing further release of $\mathrm{GH}$, it induces a trough phase at the right time and the ordinary rhythm is rapidly re-established. The twofold action of a ghrelin pulse in the brain, stimulating the release of GHRH and SRIF via NPY, resets on the one hand the GHRH cycle and on the other hand the SRIF/GH cycle. This could be used as a resetting mechanism to synchronize the GH rhythm with the day-night cycle. The resetting mechanism might be linked to a possible role of ghrelin-synthesizing neurons in the hypothalamus; however, further experiments, which focus on the GH recovery phase, are necessary to establish this hypothesis.

To summarize, our simulations lead to the following putative model of the major interactions between the GH neuroendocrine axis and ghrelin-signaling pathways (Fig. 3). Short-term effects (pulses) of stomach-derived ghrelin in the circulation give rise to a) GH-releasing activity mediated by GHS-R on somatotroph cells in the pituitary, and b) stimulation of GHRH release and food intake conveyed to the brain via the vagus nerve and NPY/AGRP neurons in the ARC. The signal transduction occurs via different pathways (circulation $\rightarrow$ pituitary $\rightarrow \mathrm{GH}$ release, and vagus nerve $\rightarrow$ brain stem $\rightarrow$ hypothalamus $\rightarrow$ GHRH and NPY secretion $\rightarrow \mathrm{GH}$ release and food intake). Our model gives rise to the hypothesis that ghrelin pulses elicited by ghrelin-containing neurons in the ARC might synchronize the GH rhythm with the lightdarkness cycle. It is still an open question why rats show such a synchronized $24 \mathrm{~h}$ rhythm (Tannenbaum \& Martin 1976) although the single oscillatory events are rather individual. This hypothesis could be tested in ghrelin knock-out animals, which should lose synchronicity if it is correct. 


\section{Declaration of interest}

We declare that there is no conflict of interest that could be perceived as prejudicing the impartiality of the research reported.

\section{Funding}

This work was supported by Grant MOP 64328 and an International Opportunity Program-Planning/Development Grant OPD-68738 (to G S Tannenbaum) from the Canadian Institutes of Health Research. GS T holds a Career Investigator Award from the Fonds de la recherche en Santé du Québec.

\section{Acknowledgements}

We gratefully acknowledge the excellent technical assistance of Zehra J Khoja and J Pablo Maianti. We thank Julie Temko for assistance in preparing the manuscript, and the NIDDK and Dr A F Parlow for the provision of GH RIA materials.

\section{References}

Akamizu T, Takaya K, Irako T, Hosada H, Teramukai S, Matsuyama A, Tada H, Miura K, Shimizu A, Fukushima M et al. 2004

Pharmacokinetics, safety, and endocrine and appetite effects of ghrelin administration in young healthy subjects. European Journal of Endocrinology 150 447-455.

Avram AM, Jaffe CA, Symons KV \& Barkan AL 2005 Endogenous circulating ghrelin does not mediate growth hormone rhythmicity or response to fasting. Journal of Clinical Endocrinology and Metabolism $902982-2987$.

Banks WA, Tschop M, Robinson SM \& Heiman ML 2002 Extent and direction of ghrelin transport across the blood-brain barrier is determined by its unique primary structure. Journal of Pharmacology and Experimental Therapeutics 302 822-827.

Bowers CY 2005 Octanoyl ghrelin is hypothalamic rooted. Endocrinology 146 2508-2509.

Bowers CY, Sartor AO, Reynolds GA \& Badger TM 1991 On the actions of the growth hormone-releasing hexapeptide, GHRP. Endocrinology 128 2027-2035.

Burton KA, Kabigting EB, Clifton DK \& Steiner RA 1992 Growth hormone receptor messenger ribonucleic acid distribution in the adult male rat brain and its colocalization in hypothalamic somatostatin neurons. Endocrinology 131 958-963.

Camina JP, Carreira MC, El Messari S, Llorens-Cortes C, Smith RG \& Casanueva FF 2004 Desensitization and endocytosis mechanisms of ghrelin-activated growth hormone secretagogue receptor la. Endocrinology 145 930-940.

Casanueva FF, Camina JP, Carreira MC, Pazos Y, Varga JL \& Schally AV 2008 Growth hormone-releasing hormone as an agonist of the ghrelin receptor GHS-R1a. PNAS 105 20452-20457.

Chapman IM, Helfgott A \& Willoughby JO 1991 Disappearance half-life times of exogenous and growth hormone-releasing factor-stimulated endogenous growth hormone in normal rats. Journal of Endocrinology 128 369-374.

Cummings DE, Purnell JQ, Frayo RS, Schmidova K, Wisse BE \& Weigle DS 2001 A preprandial rise in plasma ghrelin levels suggests a role in meal initiation in humans. Diabetes 50 1714-1719.

Cunha SR \& Mayo KE 2002 Ghrelin and growth hormone (GH) secretagogues potentiate GH-releasing hormone (GHRH)-induced cyclic adenosine $3^{\prime}, 5^{\prime}$-monophosphate production in cells expressing transfected GHRH and GH secretagogue receptors. Endocrinology 143 4570-4582.
Cunningham BC, Ultsch M, De Vos AM, Mulkerrin MG, Clauser KR \& Wells JA 1991 Dimerization of the extracellular domain of the human growth hormone receptor by a single hormone molecule. Science 254 821-825.

Date Y, Murakami N, Kojima M, Kuroiwa T, Matsukura S, Kangawa K \& Nakazato M 2000 Central effects of a novel acylated peptide, ghrelin, on growth hormone release in rats. Biochemical and Biophysical Research Communications 275 477-480.

Date Y, Murakami N, Toshinai K, Matsukura S, Niijima A, Matsuo H, Kangawa K \& Nakazato M 2002 The role of the gastric afferent vagal nerve in ghrelin-induced feeding and growth hormone secretion in rats. Gastroenterology 123 1120-1128.

Dickson SL \& Luckman SM 1997 Induction of $c$-fos messenger ribonucleic acid in neuropeptide $\mathrm{Y}$ and growth hormone $(\mathrm{GH})$ releasing factor neurons in the rat arcuate nucleus following systemic injection of the GH secretagogue, GH-releasing peptide-6. Endocrinology 138 771-777.

Fairhall KM, Mynett A \& Robinson IC 1995 Central effects of growth hormone-releasing hexapeptide (GHRP-6) on growth hormone release are inhibited by central somatostatin action. Journal of Endocrinology 144 555-560.

Farhy LS \& Veldhuis JD 2004 Putative GH pulse renewal: periventricular somatostatinergic control of an arcuate-nuclear somatostatin and GH-releasing hormone oscillator. American Journal of Physiology. Regulatory, Integrative and Comparative Physiology 286 R1030-R1042.

Farhy LS \& Veldhuis JD 2005 Deterministic construct of amplifying actions of ghrelin on pulsatile growth hormone secretion. American Journal of Physiology. Regulatory, Integrative and Comparative Physiology 288 R1649-R1663.

Farhy LS, Bowers CY \& Veldhuis JD 2007 Model-projected mechanistic bases for sex differences in growth hormone regulation in humans. American Journal of Physiology. Regulatory, Integrative and Comparative Physiology 292 R1577-R1593.

Grouzmann E, Fathi M, Gillet M, de Torrenté A, Cavadas C, Brunner H \& Buclin T 2001 Disappearance rate of catecholamines, total metanephrines, and neuropeptide $\mathrm{Y}$ from the plasma of patients after resection of pheochromocytoma. Clinical Chemistry $\mathbf{4 7}$ $1075-1082$.

Howard AD, Feighner SD, Cully DF, Arena JP, Liberator PA, Rosenblum CI, Hamelin M, Hreniuk DL, Palyha OC, Anderson J et al. $1996 \mathrm{~A}$ receptor in pituitary and hypothalamus that functions in growth hormone release. Science 273 974-977.

Kojima M, Hosoda H, Date Y, Nakazato M, Matsuo H \& Kangawa K 1999 Ghrelin is a growth-hormone-releasing acylated peptide from stomach. Nature 402 656-660.

Mogi K, Yonezawa T, Chen DS, Li JY, Suzuki M, Yamanouchi K, Sawasaki T \& Nishihara M 2004 Relationship between growth hormone $(\mathrm{GH})$ pulses in the peripheral circulation and GH-releasing hormone and somatostatin profiles in the cerebrospinal fluid of goats. Journal of Veterinary Medical Science $\mathbf{6 6}$ 1071-1078.

Muller EE, Locatelli V \& Cocchi D 1999 Neuroendocrine control of growth hormone secretion. Physiological Reviews 79 511-607.

Murakami N, Hayashida T, Kuroiwa T, Nakahara K, Ida T, Mondal MS, Nakazato M, Kojima M \& Kangawa K 2002 Role for central ghrelin in food intake and secretion profile of stomach ghrelin in rats. Journal of Endocrinology 174 283-288.

Nass R, Farhy LS, Liu J, Prudom CE, Michael JL, Veldhuis P, Pezzoli SS, Oliveri MC, Gaylinn BD, Geysen HM et al. 2008 Evidence for acyl-ghrelin modulation of growth hormone release in the fed state. Journal of Clinical Endocrinology and Metabolism 93 1988-1994.

Nogueiras R, Tovar S, Mitchell SE, Rayner DV, Archer ZA, Dieguez C \& Williams LM 2004 Regulation of growth hormone secretagogue receptor gene expression in the arcuate nuclei of the rat by leptin and ghrelin. Diabetes 53 2552-2558.

Pierroz DD, Catzeflis C, Aebi AC, Rivier JE \& Aubert ML 1996 Chronic administration of neuropeptide $\mathrm{Y}$ into the lateral ventricle inhibits 
both the pituitary-testicular axis and growth hormone and insulinlike growth factor I secretion in intact adult male rats. Endocrinology 137 3-12.

Rettori V, Milenkovic L, Aguila MC \& McCann SM 1990 Physiologically significant effect of neuropeptide $\mathrm{Y}$ to suppress growth hormone release by stimulating somatostatin discharge. Endocrinology 126 2296-2301.

Roberts JL, Mani SK, Woller MJ, Glucksman MJ \& Wu T-J 2007 LHRH-(1-5): a bioactive peptide regulating reproduction. Trends in Endocrinology and Metabolism 18 386-392.

le Roux CW, Neary NM, Halsey TJ, Small CJ, Martinez-Isla AM, Ghatei MA, Theodorou NA \& Bloom SR 2005 Ghrelin does not stimulate food intake in patients with surgical procedures involving vagotomy. Journal of Clinical Endocrinology and Metabolism 90 4521-4524.

Sato T, Fukue Y, Teranishi H, Yoshida Y \& Kojima M 2005 Molecular forms of hypothalamic ghrelin and its regulation by fasting and 2-deoxy-D-glucose administration. Endocrinology 146 2510-2516.

Smith RG, Cheng K, Pong S-S, Leonard RJ, Cohen CJ, Arena JP, Hickey GJ, Chang CH, Jacks TM, Drisko JE et al. 1996 Mechanism of action of GHRP-6 and nonpeptidyl growth hormone secretagogues. In Growth Hormone Secretagogues, pp 147-163. Eds BB Bercu \& RF Walker. New York, NY, USA: Springer-Verlag.

Tannenbaum GS \& Ling N 1984 The interrelationship of growth hormone $(\mathrm{GH})$-releasing factor and somatostatin in generation of the ultradian rhythm of GH secretion. Endocrinology 115 1952-1957.

Tannenbaum GS \& Martin JB 1976 Evidence for an endogenous ultradian rhythm governing growth hormone secretion in the rat. Endocrinology 98 562-570.

Tannenbaum GS, Lapointe M, Beaudet A \& Howard AD 1998 Expression of growth hormone secretagogue-receptors by growth hormone-releasing hormone neurons in the mediobasal hypothalamus. Endocrinology 139 4420-4423.
Tannenbaum GS, Epelbaum J \& Bowers CY 2003 Interrelationship between the novel peptide ghrelin and somatostatin/growth hormone-releasing hormone in regulation of pulsatile growth hormone secretion. Endocrinology 144 967-974.

Tolle V, Zizzari P, Tomasetto C, Rio M-C, Epelbaum J \& Bluet-Pajot M-T 2001 In vivo and in vitro effects of ghrelin/motilin-related peptide on growth hormone secretion in the rat. Neuroendocrinology $\mathbf{7 3}$ $54-61$.

Tolle V, Bassant M-H, Zizzari P, Poindessous-Jazat F, Tomasetto C, Epelbaum J \& Bluet-Pajot M-T 2002 Ultradian rhythmicity of ghrelin secretion in relation with $\mathrm{GH}$, feeding behavior, and sleep-wake patterns in rats. Endocrinology 143 1353-1361.

Tschöp M, Smiley DL \& Heiman ML 2000 Ghrelin induces adiposity in rodents. Nature 407 908-913.

Wagner C, Caplan SR \& Tannenbaum GS 1998 Genesis of the ultradian rhythm of growth hormone secretion: a new model unifying experimental observations in rats. American Journal of Physiology. Endocrinology and Metabolism 275 E1046-E1054.

White JD 1993 Neuropeptide Y: a central regulator of energy homeostasis. Regulatory Peptides 49 93-107.

Willesen MG, Kristensen P \& Romer J 1999 Co-localization of growth hormone secretagogue receptor and NPY mRNA in the arcuate nucleus of the rat. Neuroendocrinology 70 306-316.

Zizzari P, Halem H, Taylor J, Dong JZ, Datta R, Culler MD, Epelbaum J \& Bluet-Pajot MT 2005 Endogenous ghrelin regulates episodic growth hormone $(\mathrm{GH})$ secretion by amplifying $\mathrm{GH}$ pulse amplitude: evidence from antagonism of the GH secretagogue-Rla receptor. Endocrinology 146 3836-3842.

Received in final form 17 April 2009

Accepted 9 May 2009

Made available online as an Accepted Preprint 9 May 2009 